\title{
Pakistani Budget 2013-2014: A Critical Discourse Analysis
}

\author{
Illahi Bux Gopang ${ }^{1} \&$ Dr. Faraz Ali Bughio ${ }^{2}$ \\ ${ }^{1}$ Department of English, Lasbela University, Pakistan \\ ${ }^{2}$ Institute of English Language and Literature, University of Sindh, Pakistan
}

Received: October 14, 2014 Accepted: November 15, 2014 Online Published: December 10, 2014

doi:10.5430/ijelt.v2n1p40 URL: http://dx.doi.org/10.5430/ijelt.v2n1p40

\begin{abstract}
The purpose of this study is critical discourse analysis of Sindhi, Urdu and English newspaper headlines about Pakistani budget 2013-2014. The selection of newspapers headlines is random purposed from popular newspapers on June 13, 2013. The current study tends to explore the representations of the same news items in local newspapers in different ways which are ideologically contested. In addition, the critical study shows that hidden ideology of newspaper editors whose interest is to arouse public with the formation and use of emotive vocabulary. Furthermore, the linguistic devices of CDA are also the concern of this study. The significance of this study lies in the wording or vocabulary of newspapers which is the best mode of representing ideology. The conclusion of the study points out that newspaper headlines are ideological based representations of budget 2013-2014 of Pakistan. These ideological representations are treated in different ways by different newspaper editors by keeping in mind the society. Along with thematic analysis, the linguistic analysis of headlines indicates that newspapers are concealed with meaningful orientations for the readers.
\end{abstract}

Keywords: Critical Discourse Analysis, media discourse, language and ideology, headlines of Pakistani budget

\section{Introduction}

Critical Discourse Analysis (CDA) is a new field of study and it has created a number of ways for the researchers to explore the concealed ideologies behind any discourse which otherwise is taken for granted. However, linguistic analysis is an important tool for such studies. According to Taiwo (2007) language not only reflects reality but it also creates reality. Our words are never neutral, they have the power which reflects the interests of those who speak or write. For the present study, the researchers have chosen CDA of newspaper headlines dealing with Pakistani budget announcement in the Parliament for the fiscal year 2013-2014, which is an important national issue. Generally, news headlines are ways of offering rich information to people who are busy and cannot read the whole of articles, stories (Taiwo, 2007). This article is an attempt to find out the hidden meanings of seemingly simple statements of news headlines which might reveal themselves as a complex phenomenon and can have potential to influence its readers differently even though they deal with the same issue.

\subsection{Critical Discourse Analysis}

Critical Discourse Analysis basically studies social forms of society such as: inequality, dominance, social power abuse, and how these forms are enacted, legitimized, reproduced, and resisted by text and talk in the social and political context (Van Dijk, 1993). According to Fairclough and Wodak (1997) there are some basic tenets of CDA. First, CDA addresses social problems. Second, it does ideological work. Third, it constitutes society and culture. Fourth, discourse analysis is interpretative and explanatory. Van Dijk (1993) argues that language use, discourse, verbal interaction and communication belong to the micro-level of the social order. In contrast, power, dominance, and inequality between social groups belong to macro-level of analysis. CDA is primarily interested and motivated by pressing social issues, which is an attempt to better understand through discourse analysis (Van Dijk, 1988). Further, he claims that critical discourse analysis is far from easy. It seems that it is by far the toughest challenge in the discipline. As suggested above, it requires true multidisciplinary and an account of intricate relationships between text, talk, social cognition, power, society and culture. However, Wodak and Meyer (2008) mention that in general, critical discourse analysis as a school or paradigm is characterized by a number of principles: for example, all approaches are problem-oriented, and thus necessarily interdisciplinary and eclectic. Moreover, CDA is characterized by the common interests in de-mystifying ideologies and power through the systematic and retroductable 
investigation of semiotic data (written, spoken or visual). Further, Wodak and Meyer, (2008) describe that CDA emphasizes the need for interdisciplinary work in order to gain a proper understanding of how language functions in constituting and transmitting knowledge, in organizing social institutions or in exercising power.

\subsection{Media Discourse}

According to Van Dijk (1988), media discourse in general, and news reports in particular, should also be accounted for in their own right, i.e., as particular type of language use or text as specific kinds of socio-cultural practice. The power of media is undeniable because it has inspired many critical studies in many disciplines: linguistics, semiotics, pragmatics, and discourse studies (Van Dijk, 1993). In the interpretation of news media, Van Dijk (1988) explores the notion of media news in every day usage and gives the concepts such as; (1) new information about events, things or persons; (2) a (TV or radio) program type in which news items are presented; (3) a news item or news report, i.e., a text or discourse on radio, on TV or in the newspaper, in which new information is given about recent events (Van Dijk, 1988). However, Fowler (1991) interprets news as a product shaped by political, economic, and cultural forces, not as a reflection of reality. He also emphasizes the tools of linguistics such as: the analysis of transitivity in syntax, lexical structure, modality, and speech acts. News is not characterized as a picture of reality, which may be correct or biased, but as a frame through which the social world is routinely constructed (Van Dijk, 1988). In addition, he also argues that news should be studied primarily as a form of public discourse. In the literature of newspaper, mass communication research, the economic, social, or cultural dimensions of news and news media are addressed.

\subsection{Language, Ideology and Power}

Research has suggested the significance of ideology and power and the role of language in maintaining and reinforcing them. Van Dijk (1988) claims that ideologies organize social group attitudes consisting of schematically organized general opinions about relevant social issues, such as, inequality, dominance, power abuse. Since ideologies are the basis of our social judgments, and ideologically controlled propositions often are opinion statements, expressions of such opinions, e.g., those about others will often indicate what ideological constraints are involved (Van Dijk, 1988). According to Fairclough (2003), ideologies are representations of aspects of the world which contribute to establishing and maintaining relations of power, domination and exploitation. They may be enacted in ways of interaction (and therefore in genres) and inculcated in ways of being identities (and therefore styles). Analysis of texts is an important aspect of ideological analysis and critique. While Van Dijk (1988, 1993, 2001) furthers the idea and argues that ideologies, just like other social representations, may have a standard schematic organization, consisting of a limited number of fixed categories. Next, ideologies are not limited to groups that are related by dominance, power or struggle. We also have professional ideologies (e.g., of journalists and professors), institutional ideologies, and ideologies of many other groups in Society. In addition, he also discusses that the point of ideological discourse analysis is not merely to discover underlying ideologies, but to systematically link structures of discourse with structures of ideologies. One needs not be a discourse analyst to conclude that a news report, textbook fragment or conversation is conservative, sexist or environmentalist (Van Dijk, 1988). According to Rogers et al., (2005, p. 367), 'language is a social practice and because not all social practices are created and treated equally, all analyses of language are critical. CDA sets out to interpret, describe, and explain the relationship between language, social practices, and the social world. Language indexes, expresses, and constitutes social relations and it also challenges them. Critical discourse analysts locate power in the arena of language as a social practice. Power, however, can take on both liberating and oppressive forms (Rogers et al., 2005). However, according to Wodak et al (2008, p. 10), 'Power is about relations of difference, and particularly about the effects of differences in social structure. The constant unity of language and other social matters ensures that language is entwined in social power in a number of ways: language indexes and expresses power, and is involved where there is contention over and a challenge to power. Power does not necessarily derive from language, but language can be used to challenge power, to subvert it, to alter distributions of power in the short and the long term. Thus language provides a finely articulated vehicle for differences in power in hierarchical social structures.

\subsection{Significance of News Paper Headlines}

It is generally assumed that the headlines of a newspaper convey a meaningful message to the readers. In this regard, Develotte et al., (2001) maintain that headlines are particularly revealing of the social, cultural and therefore national representations circulating in a society at a given time. Headlines reach an audience considerably wider than those who read the articles, since all those who buy the paper will glance, if only fleetingly, at the headlines. Moreover their impact is even wider than on those who actually buy the paper, since headlines are often glimpsed on public transport, displayed on fliers. Further, Develotte et al., (2001) discuss that headlines are a particularly rich source of information about the field of cultural references. This is because titles 'stand alone' without explanation or definition; 
they depend on the reader recognizing instantly the field, allusions, issues, cultural references necessary to identify the content of the articles. They thus rely on a stock of cultural knowledge, representations and models of reality that must be assumed to be widespread in the society if the headlines are to have meaning. Likewise, Taiwo (2007) is of the opinion that News paper headlines act as forerunners to news reports. They particularly, reveal the social, cultural and cultural representations circulating in a society at any given time. They reach an audience considerably wider than those who read the news story. As the vendors display their newspapers, several people, including passerby and casual readers are able to have a glimpse of the headlines, which may later become the subject of discussion in their offices, at home or any other domain. This is particularly true of front page headlines, which are more carefully chosen to evoke some emotions in the readers. Newspapers deliberately go for eye catching expressions.

Now the question is that what advantage of analyzing newspaper headlines is? In this context, Develotte et al (2001) state that the advantage of analyzing headlines is that they refer to and encapsulate this 'knowledge', for the reasons which we have outlined above: they rely on widely disseminated cultural knowledge in order to be understood. They thus constitute a kind of 'shorthand', a simplification and condensation of ideas. They play, moreover, both a passive and an active role: they depend on and mobilize this knowledge but also in turn help to disseminate and reinforce it; they create new associations and networks of meaning. They also seek to exploit representations for pragmatic effect. To understand how headlines perform this double role, we will examine some of the linguistic features of headlines that are particularly relevant to the study of national representations (Develotte, 2001).

According to Taiwo (2004), newspaper headlines are rich source of information about the field of culture and they can be sometimes difficult to understand especially when the reader cannot recognize the field, allusions, issues and cultural references necessary to decode the content. The reader must understand enough about what has been going on recently in the setting of the news, i.e. the reality that is assumed to be widespread in the society at that particular time.

The review of the literature shows how power of media discourse plays a role in the lives of people. Furthermore, power and ideology is incorporated in such discourse. Here is the method used to explore hidden messages in headlines of the newspapers.

\section{Methodology}

The data for the current study has been gathered from different Sindhi, Urdu and English newspapers. However, the only source of data collection is headlines of the newspapers on budget 2013-2014, Pakistan. The purpose of this study is to explore how the same issue has been treated differently in the newspapers which underlay their ideology. Thus the study is an attempt to find out their hidden ideological meanings by following CDA. The purpose is to show how the treatment of the national issue of Pakistani budget 2013-2014 is thematically and linguistically different.

\section{Data analysis and Discussion}

Data were collected from English, Sindh and Urdu newspapers which are published in Pakistan. The rationale behind this was to find out how a national issue of budget is treated differently by different newspapers. The analysis of these headlines is based on newspapers' content and structures under the principles of critical discourse analysis. It is however micro (linguistic structures) and macro (thematic) analysis of headlines which is presented in the following sections.

\subsection{Sindhi Newspaper Headlines}

According to Mahmood and Javed (2011) newspapers are considered to be a real portrayal of issues concerning national and social interests on the basis of their ideological perspectives. However, the most significant part of newspapers is news headlines which offer immediate information to those who do not have enough time to read between the lines. Sindhi newspaper headlines are provided to analyze the thematic and linguistic features of them.

1. Nawaz sarkar pihreen bajet men mahangayee jo toufan aney chadiyo, pagharun na wadhyun. Har shayee ja agh wadhee waya (Daliy Kawish, June, 13, 2013).

In the first budget, Nawaz Sharif's government has brought a storm of inflation, no increase in the salaries; rates for everything have gone high.

2. paghar na wadhe, bijlee, kheer khand chai cigarette mahinga. (Awami Awaz, June, 13, 2013,)

No increase in the salaries, increase in rates of electricity, milk, tea, cigarette, sugar. 
The researchers agree to the idea of Mahmood et al. (2011, p. 123) that all newspaper headlines are only simple statements, but these simple statements carry some hidden messages or ideologies. As Dijk (1988) sates that different ideologies are portrayed in different structures of discourse. However, in the structure of Sindhi newspapers, the above headlines help us to understand that there is a hidden agenda which is not stated directly.

The headlines of the current budget make us believe that storm of inflation has reached at the doorsteps of the masses and now there is no escape from it. While using such words the editors have concealed their ideology, which is the only belief to arouse feelings and emotions of the masses; and it is incorporated in the following words. These words serve their interests.

These words speak meaningful ideology of editors and management. The first headline of Kawish newspaper indicates that the present government has done injustice to the people of the country. The storm of inflation has swayed expectations of the people who wished decrease in prices. Basically, this idea serves hidden purpose of editors who intend that the people should stand against Nawaz government and boycott the announced budget as mentioned in the first headline of Kawish newspaper 'Nawaz sarkar pihreen bajet men mahangayee jo toufan aney chadiyo'. Broadly speaking, critical analysis suggests that ideology works effectively through language employed in the headlines.

\subsection{Urdu Newspaper Headlines}

Urdu newspaper headlines highlight the same issue of budget but in different way. However, the choice of words is also different. We agree to the idea of Fowler $(1991$, p. 4) who claims that there are always different ways of saying the same thing and they are not random, accidental alternatives. Differences in expression carry ideological distinctions and thus differences in representation.

1. G.S.T ek feesad barh gaya, haj cigarette cold drink gariyan mahingee (Nawaye Waqt)
$1 \%$ increase in General Sales Tax, rates of Pilgrimage, cigarette and cold drink go high.
2. G.S.T ek feesad barh gaya, khourdini tel, mashroyaat, pan cigarette mahingay (Express)
3. bijlee, cheeni tel ghee doudh cement, cigarette, pan chaliyan, frig air conditioner mahingay (Jang Karachi)
4. Sales tax satraan feesad, dabay ka doudh mashroubaat khourdini tel ghee makanaat mahingay (Duniya
Karachi)

As researchers we find that in Urdu newspapers, focus is on tax paying items as given above. The headlines of Urdu newspapers have smoothly touched the issue of budget extensively. The end of each newspaper headline finishes with different words which show the ideology of the editors. According to Van Dijk (1988, p. 11), "media are not neutral, common sensed or rational mediator of social events, but essentially help reproduce performulated ideologies. The purpose of focus on these words is to show how news editors play with words in order to arouse the public, keeping in view their own powerful ideology. The question of editors' interest needs to be answered here. News makers are interested to create such sensationalism; see the words in each headline, 'barh gaya', 'mahingay', mahingay' (high rates). Accroding to Fairclough (1989, p. 114-115), the most significant indication of ideology in a text is the wording or the vocabulary. For example "some words are ideologically contested. Thus, he further states that over-wording shows a preoccupation with some aspect of reality - which may indicate that it is the focus of ideological struggle.

It is however obvious the editors keep in mind the basic amenities of the people. They focus these needs because they believe that the people cannot tolerate increase in the daily use of articles. In Urdu headlines, focus of attention is sugar, pilgrimage, cold drinks, cigarettes, milk, and cooking oil. The use of words in Urdu newspapers is different other newspapers. This is an interesting art of editors to invoke the public through different language but having same intentions.

\subsection{English Newspaper Headlines}

However, the English newspapers are expected to be read by the elite class people and those who intend to join bureaucracy. Therefore, the treatment of the same issue is different. However, the editors are supposed to be of the same ideology. According to Taiwo (2004, 2007), newspaper editors work on values of society because they create their own hidden messages. It seems through the headlines that support their ideology that is to arouse the people's emotions. And they show their mastery over such phrases which dismay the people. The advantage editors have is the only publicity and marketing of their newspapers. The editors systematically and strategically use headlines, who select emotional words and rhetorical devices to create influence on the readers or readership (Taiwo, 2004). English 
newspaper headlines are presented herewith.

\begin{tabular}{|lll|}
\hline 1. & A taxing uplift budget & (The Nation) \\
2. & Bid to grapple with economic mess & (The Dawn) \\
3. & No lollipops only bitter pills in budget & (The News) \\
4. & PML-N unveils ambitious budget & (The statesman) \\
5. & A desperate budget & (Business Recorder) \\
\hline
\end{tabular}

Significantly, a message in English newspapers speaks the same ideology and power of editors. It suggests that there is no hope, no relief and no benefit for the masses. Thus, words such as, desperate, ambitious, bitter pills enrage the public and satisfy the invested interests of the editors. Above all, the critical analysis of the newspapers showed the same picture of budget (inflation) in different words. On the one hand, such emotive words play havoc with public, and on the other hand, newspaper editors do their job. Broadly speaking, newspaper headlines do not only awaken the interest of readers, but also intrigue and arouse their emotions. For example words such as "desperate" "bitter pills" "ambitious" definitely serve the purpose of newsmakers. A very common word used almost in Sindhi and Urdu newspapers is mahingay/ barh gaya/. And this makes a difference for the public. In contrast, in English newspaper, words are different but serve the same purpose. Thus, a sense of hopelessness is also carried out in English newspapers headlines. After macro analyses of newspaper headlines, micro analysis is presented wherein linguistic features of newspaper headlines are highlighted

\subsubsection{Typical Linguistic Features of Newspaper Headlines}

According to Ingrid (1980), there are some grammatical features of newspaper headlines. These features are ;(1) omission of articles; (2) omission of verbs and of auxiliaries (the verb 'to be' for example);(3) nominalizations; passivization (4) the frequent use of complex noun phrases in subject position (in theme position); (5) adverbial headlines, with the omission of both verb and subject;(6) use of short words ('bid' instead of 'attempt'); (7)widespread use of puns, word play and alliteration; (8) importance of word order, with the most important items placed first. Some of these linguistic features found in the newspaper headlines are discussed as follows:

\subsubsection{Nominalization}

Nominalization was, for instance, 'turning verbs into nouns' (Fowler et al., 1979, as cited in Billig, 2008). However, according to Cook (2008, p. 66), nominalization is when actions and processes re referred to by nouns as though they, rather than the people doing them, were the agent. The technique makes action inevitable and impersonal. In the following newspaper (Sindhi, Urdu and English) headlines, this linguistic feature is prevalent.

1. A taxing uplift budget

2. A desperate budget

3. No lollipops only bitter pills in the budget

4. Budget not beneficial for masses

5. A bid to grapple with economic mess

6. PML-N unveils ambitious budget

7. G.S.T men hikro sekro wadh, har shaye ja agh wadhe wayaa. (Kawish )

8. pghar na wadhe, difaiyee bajet men waadh, bijlee, kheer khand chai cigarette mahinga (Awami Awaz)

9. G.S.T ek feesad barh gaya, haj cigarette cold drink gariyan mahingee (Nawaye Waqt)

10. G.S.T ek feesad barh gaya, khourdini tel, mashroyaat, pan cigarette mahingay (Express)

11. bijlee, cheeni tel ghee doudh cement, cigarette, pan chaliyan, frig air conditioner mahingay (Jang Karachi)

12. sales tax satraan feesad, dabay ka doudh mashroubaat khourdini tel ghee makanaat mahingay (Duniya Karachi)

\subsubsection{Passivization}

It is a very important linguistic feature of the newspaper headlines. The news editors use this technique because they do not show agents responsible for statements. The above newspaper headlines except one," Nawaz sarkar pihreen bajet men mahangayee jo toufan aney chadiyo, pagharun na wadhyun. Har shayee ja agh wadhee waya", the agents are hidden who are responsible for the announced budget; and who terms it as desperate, no lollipops, not beneficial for masses, a taxing uplift budget, is of course not known to the readers. However, the readers are expected to 
response and evaluate the budget in quite same way.

\subsubsection{Formation of Word Order}

The use and selection of words is very purposeful and meaningful. Now the question arises why such words are selected? Van Dijk (1988) is of the view that the selection of particular words may indicate the degree of formality, speech partners, the group centered or institutional embedding of discourse, attitudes and hence the ideologies of the speaker.

1. No lollipops only bitter pills in the budget

2. Budget not beneficial for masses

3. ambitious budget

4. Toufan aanay chadiyo (brought storm of inflation)

5. Paghar $\mathrm{n}$ wadhee (no increase in salaries)

Thus it seems that the words used in media discourse play very important role in influencing the minds of the people. However, such vocabulary reveals the rationale of editors who play with the emotion of the public. It seems editors always intend to market themselves through such emotive words. Broadly speaking, this shows two aspects: invoke public or let government realize the inflation thrown on the masses, which do not live burden free life. According to Cook (2008), the use of language manipulates our feelings and thoughts though in ways which we are willing, even, eager to accept it. Further he also states other uses of language are less benign, seeking to control and influence ideas in the service of some vested political or commercial interest. However, selection of such word order makes the readers very emotional. The purpose of using such selection is to manipulate the readers' emotions and feelings towards the issue of budget

\subsubsection{Omission of Subjects and Auxiliary Verbs}

In the headlines there are no auxiliary verbs used. The technique is common in the use of newspaper headlines. The advantage of doing it is to make phrases very influential and effective for the readers.

\section{A desperate budget}

2. No lollipops only bitter pills in the budget

3. Budget not beneficial for masses

4. Sales tax satraan feesad, dabay ka doudh mashroubaat khourdini tel ghee makanaat mahingay.

5. paghar na wadhe (Awami Awaz)

With the help of CDA devices, it suggests that the use of subjects and helping or auxiliary verbs is strongly omitted. In addition, this technique makes the news makers use the short words such as (bid instead of attempt) as discussed in the linguistic features. The macro and micro analysis of newspaper headlines indicate that there are meaningful hidden ideologies which in fact speak out the objective of editors and their management. Thus, such ideology representing power is covered in some words which are pregnant with emotions. Reasonably speaking, these emotions do not have any meaning for editors but for the masses. Research suggests that language is the most powerful instrument which can be utilized to exploit and manipulate the people. As it is indicated by researchers that there are always different ways to speak the same thing and differences in ideology may result in expressions. This statement is also supported by the study of Ghannam (2011) who researched on newspaper ideology in Lebanon. The findings of this study also reveal that the same issue of national budget 2013-2014, is treated in different ways. Thus, we find that the choice of words is nicely done which is ideologically contested. For that reason we find that newspapers often try to catch the interest of the readers by using journalistic techniques of brevity and preciseness which serve the purpose of unsaid words. According to Fairclough (1989), the wording or vocabulary is the best indication of ideology in a text.

\section{Conclusion}

The critical analysis of the budget newspaper headlines shows how ideologies work in the formation of news media discourse. Further, with the help of CDA, the findings of the study indicate that how simple statements carry editors' hidden ideology, and their power of using over-wording in a text to serve their purpose. However, the editors aim at presenting the news which may make the readers very emotional against the present government. It is one of the interests of news editors to select such headlines which mould and shape the thinking of the people. This perception 
is justifiable in words such as "no lollipops only bitter pills in the budget. Critical discourse analysis has helped researchers to explore unrevealed ideologies. A discourse analysis also indicates that headlines are exploited to form discourse on national issues. On such issues like budget, all the newspapers sang the sad song of inflation which truly represented invested interests of editors and their management. In Pakistan, critical discourse analysis needs to be used to critically examine the true picture beyond the published words in newspapers.

\section{Acknowledgments}

We thank Dr. Nadeem Haider Bukhari for his critical comments on the paper. We are also thankful to our faculty for some proof reading.

\section{References}

Billig, M. (2008). The language of critical discourse analysis: The case of nominalization. Discourse and Society, 19(6), 783-800. Sage Publications.

Cook, G. (2008). Applied linguistics. Oxford University Press

Develotte, C., \& Rechniewski, E. (2001). Discourse analysis of newspaper headlines: A methodological framework for research into national representations. Web Journal of French Media Studies, 4(1).

Fairclough, N. (1989). Language and Power. London and New York: Longman.

Fairclough, N., \& Wodak, R. (1997a). Critical discourse analysis. In T. van Dijk (Ed.), Discourse as social interaction (pp. 258-284). London: Sage Publications

Fairclough, N. (2003b). Analyzing discourse. London: Routledge.

Fowler, R. (1991). Language in the news: Discourse and ideology in the press. London: Routledge.

Ghannam, N. (2011). Newspaper ideology: A critical discourse analysis of an event published in six Lebanese newspapers. (M.A dissertation), University of the Witwatersrand, South Africa.

Ingrid, M. (1980). Headlines: On the grammar of English front page headlines. Malmo.

Mahmood, M, A., Javed, S., \& Mahmood, R. (2012). A critical discourse analysis of the news headlines of budget of Pakistan FY 2011-2012. Interdisciplinary Journal of Contemporary Research in Business, 3(5).

Rogers, R., Berkes, L, M., Mosley, M., Hui, D., \& Joseph, G. O. (2005). Critical discourse analysis in education: A review of the literature. Review of Education Research, 75(3), 365-416.

Taiwo, R. (2004). Speech as headline in Nigerian newspapers. In Segun Awonusi, \& E. A. Babalola (Eds), The domestication of English in Nigeria (pp. 323-335). Lagos: University of Lagos Press 2004.

Taiwo, R. (2007). Language, ideology and power relations in Nigerian newspaper headlines. Nebula, 4(1), 218-245.

Van Dijk, T. A. (1988a). News analysis. Case studies of international and national news in the press. Hillsdale, NJ: Erbaum.

Van Dijk, T. A. (1988b). News analysis. Hillsdale: Erlbaum.

Van Dijk, T. A. (1993). Principles of critical discourse analysis. Discourse and Society, 4(2), 249-283.

Van Dijk, T. A. (2001). Critical discourse analysis. Handbook of discourse analysis. Oxford Blackwell.

Wodak, R., \& Meyer, M. (2008). Critical discourse analysis: History, agenda, theory, and methodology. Sage publications. 